\title{
Short communication: Evaluation of Brucella infection of cows by PCR detection of Brucella DNA in raw milk
}

\author{
P. Ning, ${ }^{1}$ K. Guo, ${ }^{1}$ L. Xu, R. Xu, C. Zhang, Y. Cheng, H. Cui, W. Liu, Q. Lv, W. Cao, and Y. Zhang ${ }^{2}$ \\ College of Veterinary Medicine, Northwest A \& F University, Yangling, Shaanxi 712100, PR China
}

\begin{abstract}
The collection of serum samples from cows is frequently difficult to implement in large-scale surveys, and may involve a high risk of occupational infection. This study assessed the potential of using raw milk sampling as a suitable method for use in a pilot survey of Brucella abortus infection status in cattle. Raw milk samples from 816 cows were examined. Polymerase chain reaction assays of raw milk, with primers derived from the IS711 element of the Brucella genome, were used. Of the cows, 55 were Brucella positive based on serum agglutination test (SAT) results. Polymerase chain reaction amplified Brucella DNA in 25 (45\%) of the 55 SAT-positive cows. All of the 689 SAT-negative cows were found to be negative in PCR assays of their milk. Brucella infection status based on PCR results was then predicted for 72 cows from private herds in which the brucellosis status was unknown. Subsequently, SAT verification of Brucella status was performed. There was no significant difference between predicted and actual SAT-positive rates in those 72 cows. This study indicates a relationship between Brucella detection levels obtained using milk-based PCR results and SAT results. The specific, rapid, and easy sampling procedure within milk-based PCR assaying for brucellosis detection makes the milk PCR method an attractive alternative for evaluation of $B$. abortus infection in cows, particularly if used as a routine screening and surveillance tool to reduce brucellosis outbreaks.
\end{abstract}

Key words: brucellosis, cow milk, PCR

\section{Short Communication}

Brucellosis is a globally distributed zoonosis caused by Brucella, a bacterium that is easily transmitted among domesticated animals (cattle, sheep, goats, pigs, and buffalo; Corbel, 2006). Brucellosis has important effects on both human health and animal health, and

Received April 6, 2012.

Accepted May 13, 2012.

${ }^{1}$ These authors contributed to this paper equally.

${ }^{2}$ Corresponding author: zhangym@nwsuaf.edu.cn brucellosis results in large economic losses in animal production as a consequence of abortion, sterility, decreased milk production, reduced reproduction date, and the cost of culling animals (Gwida et al., 2010). Brucellosis in humans is not considered contagious, as people typically become infected by contact with fluids from infected animals or by consumption of raw animal products such as unpasteurized milk and undercooked meat products (Malik, 1997; Earhart et al., 2009).

An estimate of the worldwide incidence of brucellosis is hard to obtain because of low levels of inspection and reporting in many Brucella endemic areas. Failure to monitor for brucellosis, which frequently presents as a chronic disease, is largely due to a lack of an appropriate evaluation and alarm mechanisms. In addition, there may be an absence of convenient sampling and testing methods suitable for large-scale screening. Bacterial isolation is a good standard for use in obtaining diagnoses (Alton et al., 1975), but it requires a long cultivation period, which is often unsuccessful, and increases the risk of humans contracting laboratoryacquired brucellosis along with increased numbers of isolates of Brucella (Gruner et al., 1994; Martin-Mazuelos et al., 1994). The serum agglutination test (SAT) is still widely used for the diagnosis of brucellosis, and is specified for use in many countries including China. However, it is difficult to adopt an approach that collects serum samples in large-scale surveys because of the potential for an increased risk of occupational infections (Bouza et al., 2005).

In this study, milk instead of blood serum was investigated as a convenient, noninvasive source of material from which to obtain Brucella infection information. A PCR method was used to detect Brucella antigens in milk samples. This method was selected because it is sensitive, specific, rapid, and relatively inexpensive (Bricker, 2002). A specific region of the Brucella genome, the IS711 element downstream of the alkB gene, was targeted in our PCR assays. Assessments using IS711 have been carried out on milk samples in earlier studies (Hamdy and Amin, 2002; O'Leary et al., 2006). The aim of the present study focused on 2 aspects in its large sample size analysis: (1) to investigate the Brucella-positive rate in raw milk from serologically 
positive cows and (2) to evaluate the practicality of using raw milk as the sample source for a pilot survey on Brucella abortus infections in a cattle herd.

Eight hundred and sixteen cows were included in this study. The animals were divided into 3 groups based on their brucellosis status, and from each cow, a raw milk sample was collected. Group A comprised 55 cows, from different areas within China, with Brucella-positive SAT results during the March 2010 to November 2011 period. Group B ( $\mathrm{n}=689$; control group) consisted of serologically negative cows that came from 3 Brucellafree farms in China. Group C consisted of 72 cows with unknown brucellosis status. They were privately owned within several individual households in 2 villages (C-I and C-II) in China.

A questionnaire-based presurvey was administered to farm owners and households to collect information on previous Brucella infections, Brucella vaccination status, herd abortion rate, herd size, and management style. Milk samples from each animal were collected into Whirl-Pak (Nasco, Salida, CA) sampling bags. Collections were done after thorough povidone-iodine disinfection of the teat area. For each sample, $50 \mathrm{~mL}$ of milk was drawn into an aseptic sampling bag, after which the bags were closed and stored refrigerated until needed.

The Brucella DNA extraction and purification method used in this study was as described by Gupta et al. (2006). Briefly, the precipitate obtained after centrifugation of $50-\mathrm{mL}$ milk samples at $12,000 \times g$ for 5 min was resuspended to form a $500-\mu \mathrm{L}$ suspension by mixing with $100 \mu \mathrm{L}$ of TE buffer (1 mM EDTA and $10 \mathrm{~m} M$ Tris-HCl; $\mathrm{pH} 7.6)$. To that mixture, $100 \mu \mathrm{L}$ of $24 \%$ sodium dodecyl sulfate was added as a denaturing agent. The mixture was incubated at $100^{\circ} \mathrm{C}$ for $10 \mathrm{~min}$ and then cooled on ice. Proteinase K (Sigma-Aldrich Co. LLC, St. Louis, MO; $650 \mu \mathrm{g} / \mathrm{mL}$ ) was added and the mixture was kept at $37^{\circ} \mathrm{C}$ for $2 \mathrm{~h}$. The cell debris was removed by precipitation with a $5 \mathrm{M} \mathrm{NaCl}$ and hexadecyltrimethylammonium bromide- $\mathrm{NaCl}$ solution at $65^{\circ} \mathrm{C}$ for $10 \mathrm{~min}$. Deoxyribonucleic acid was extracted by standard methods with a phenol-chloroform-isoamyl alcohol mixture (25:24:1), and then precipitated with isopropanol, washed with ethanol, and dried under vacuum. The obtained DNA pellet was dissolved in 25 $\mu \mathrm{L}$ of sterile distilled water and stored at $20^{\circ} \mathrm{C}$ until needed.

The sequences of oligonucleotide primers used in this study were 5'-GAGAAT AAAGCCAACACCCG-3' and 5'-GATGGACGAAACCCACGAAT-3'. The primers were used to amplify a 317-bp target sequence that included the gene-coded IS711 region of the Brucella genome. The 25- $\mu \mathrm{L}$ PCR mixtures contained $2.5 \mathrm{U}$ of Easy-A Taq DNA polymerase, $1 \times$ Easy-A Taq buffer (Agilent Technologies Inc., Santa Clara, CA), $2 \mathrm{mM}$ $\mathrm{MgCl}_{2}, 2.5 \mathrm{~m} M$ concentration for each deoxynucleoside triphosphate, $40 \mathrm{pmol}$ of each primer, and $100 \mathrm{ng}$ of purified genomic DNA. Polymerase chain reaction was performed in a thermocycler (Bio-Rad Laboratories Inc., Hercules, CA) as follows: $95^{\circ} \mathrm{C}$ for $3 \mathrm{~min}$ for denaturation, 30 cycles of $95^{\circ} \mathrm{C}$ for $30 \mathrm{~s}, 58^{\circ} \mathrm{C}$ for $30 \mathrm{~s}$, $72^{\circ} \mathrm{C}$ for $30 \mathrm{~s}$, and finally $72^{\circ} \mathrm{C}$ for $10 \mathrm{~min}$. The PCR products were fractionated in a $1.5 \%$ (wt/vol) agarose gel containing $1 \times \mathrm{TBE}(100 \mathrm{~m} M$ Tris- $\mathrm{HCl}, \mathrm{pH}$ 8.0; 90 $\mathrm{m} M$ boric acid; and $1 \mathrm{~m} M$ disodium EDTA), stained with an ethidium bromide solution $(0.5 \mathrm{mg} / \mathrm{mL})$, visualized under an UV transilluminator (Bio-Rad Laboratories Inc.), and photographed. Visible bands of sizes appropriate to be representative of the 317-bp target sequence of Brucella were considered IS711-positive products. Each sample was replicated 3 times to obtain consistent PCR results.

Statistical analyses of the collected data was performed using SPSS 13.0 software (SPSS Inc., Chicago, IL). A $P$-value less than 0.05 was considered significant.

The objective of the present research was to assess the animal's Brucella infection status by detecting the presence of Brucella DNA in raw milk. The PCR assays amplified Brucella DNA in 25 (45\%) of the 55 raw milk samples obtained from cows that were positive to the SAT (group A; Table 1). The control group (group B) contained 689 milk samples collected from 3 Brucellafree farms. All 689 milk samples were Brucella-negative in the PCR assays, indicating that the specificity of the milk-based PCR assessment was 100\% in serologically negative herds.

Table 1. Relationship between PCR-positive and serum agglutination test (SAT)-positive rates

\begin{tabular}{lccccc}
\hline Group & Animals (no.) & $\begin{array}{c}\text { Detected PCR+ } \\
\text { in milk sample (no.) }\end{array}$ & $\begin{array}{c}\text { Predicted SAT+ } \\
\text { in animal serum (no.) }\end{array}$ & $\begin{array}{c}\text { Detected SAT+ } \\
\text { in animal serum (no.) }\end{array}$ & $\begin{array}{c}\text { Detected PCR+ } \\
\text { in detected SAT+ (\%) }\end{array}$ \\
\hline A & 55 & 25 & - & 55 & 45 \\
B & 689 & 0 & - & 15 & 47 \\
C-I & 48 & 7 & 20 & 19 & 47 \\
C-II & 25 & 16 & 36 & 34 & 47 \\
C & 73 & & & & 0 \\
\hline
\end{tabular}


The group A results indicate a relationship between PCR-derived and SAT-derived Brucella-positive rates. That relationship was used to predict the Brucella infection status of cows in group C. The PCR assays were performed on the 73 milk samples from cows in group $\mathrm{C}$ and 16 samples were found to be Brucella DNA positive (Table 1). By applying the $45 \%$ milk PCR detection rate in SAT Brucella-positive cows of group A to the 16 Brucella-DNA positive milk samples in group $\mathrm{C}$ it was predicted that 36 cows in group $\mathrm{C}$ would be Brucella positive in SAT-based testing. An SAT verification survey was performed on the serum of the 73 cows in group $\mathrm{C}$ and 34 were determined to be Brucella positive. Among the 34 Brucella-positive cows in the SAT results, 16 were Brucella positive in the milk PCR results. All cows that were Brucella positive in the milk PCR results were also positive in the SAT results, whereas $47 \%$ of the Brucella-positive cows in the $\mathrm{SAT}$ results were also positive in the PCR results. The predicted and actual SAT-positive rates were compared and no significant difference was detected $(P>0.05)$.

In addition, similar analysis was undertaken separately for the group $\mathrm{C}$ cows from 2 villages (subgroups C-I and C-II). Seven and 9 cows were Brucella positive in subgroups C-I and C-II, respectively. Based on the Brucella-positive rate in group A, 16 and 20 Brucellapositive cows were predicted to be present in subgroups C-I and C-II, respectively (Table 1). Serum agglutination test verification sampling was performed to determine the actual Brucella-positive rate in subgroups C-I and C-II. No significant difference $(P>0.05)$ was detected between predicted and actual results in either of the subgroups, even though the subgroup SAT-positive rates ranged from 31 to $76 \%$.

Human Brucella infections arise through direct contact with infected animals or their products. Different dietary customs in different countries or regions result in raw milk being sold directly by raw milk producers in some countries (Falenski et al., 2011). In infected dairy animals, Brucella is localized in the tissues of the udder and is excreted along with milk throughout the animals' lives (Cordes and Carter, 1979). Brucella can survive for at least $4 \mathrm{~d}$ in water or milk (Falenski et al., 2011). In addition, the infectious dose of Brucella is very low; thus, occupational infection risks exist for farmers, milkers, and others who work in facilities processing milk and milk products. Such risks are of particular concern for workers with herds such as those in group A. However, for workers with herds such as those in group B, few or no Brucella-related risks exist.

Although adequate control programs, which include both vaccination and eradication, have been successful in China, insufficient preventive measures and controls on private animal management exist in some remote or ethnic-minority areas. These deficiencies increase the risk of a spread in Brucella distribution. In this study, milk from the cows in group $\mathrm{C}$ was for personal use within 2 villages. A questionnaire-based survey revealed high abortion rates in the villages' cows, instances of cattle and sheep breeding together, nonstandard infection eradication methods, and individual people that, on occasion, drink raw milk. All such factors increase the risk of brucellosis occurrence (Al-Majali et al., 2007). For examination of Brucella presence in group $\mathrm{C}$ (cows that had not undergone an SAT) the PCRbased results from milk in group A (cows known to have brucellosis) were used to predict the presence of Brucella in group C. Subsequently, the SAT verified the existence of brucellosis infection in some of the group $\mathrm{C}$ cows. No significant difference was observed between the predicted and actual SAT-based Brucella-positive rates. On the basis of the SAT results, serologically positive cows in group $\mathrm{C}$ have now been slaughtered in accordance with the National Eradication Program in China; thus, a source of risk for brucellosis infection in those villages has been reduced by this survey.

Brucella is fastidious and difficult to detect in clinical samples. In addition, Brucella is a significant aerosol biohazard in laboratory situations (Sewell, 1995; Fiori et al., 2000). Although serological testing methods such as ELISA and milk ring test have been used to detect anti-Brucella antibodies in milk (Vanzini et al., 2001; Chand et al., 2005), the results may be confused by the extensive use of vaccines, which can gave rise to antibody responses similar to those resulting from the target infection (Nielsen, 2002). Therefore, PCR amplification targeting the IS711 element was performed to determine the presence of Brucella DNA in milk samples. Amplification of the $317 \mathrm{bp}$ IS711 fragment by targeted PCR demonstrated the Brucella DNA in $45 \%$ of the 55 milk samples from cows with serologically confirmed brucellosis. This percentage is similar to that in work by O'Leary et al. (2006) who detected 9 PCR-positive milk samples from 21 serologically positive cows. Similar results were obtained by Hamdy and Amin (2002), who reported Brucella DNA in 53 milk samples from 92 SAT-positive animals.

These results indicate that the Brucella detection rate using raw milk and PCR is lower than that when using the SAT. This difference may be attributed to several factors. First, it may be related to the intermittent character of an organism's milk excretion (Arellano-Reynoso et al., 2004; O'Leary et al., 2006). Brucella can vary in their localization in mammary glands after cattle are infected (Xavier et al., 2009), and bacteria present in lymph nodes may be intermit- 
tently shed into milk. Second, it may be attributed to variation in infection status. The stage of infection of the cows in this work was not known and variation in the cows' infection stage could have affected our results. Among individuals, both infection stages and antibody responses to Brucella may not be synchronous. Third, PCR detection limits may affect the study's detection rate, as differences in PCR sensitivity in the diagnosis of brucellosis have been reported. To assess this factor, we determined the detection limit of Brucella DNA in milk by using sterile milk inoculated with a known concentration of Brucella. A positive PCR result was always obtained when using different aliquots containing at least $100 \mathrm{cfu} / \mathrm{mL}$ of milk. Fourth, PCR sensitivity may have affected the study's results, as PCR sensitivity is primarily affected by the efficiency of the DNA extraction procedure and the amount of sample processed in the assay (Romero and Lopez-Goñi, 1999). In the current study, consistent procedures and sample sizes were used. Thus, the detection of Brucella in milk should be carried out using the same DNA extraction procedure in promising screening activities.

Despite those potential limitations, we suggest that milk sampling is a simpler and more convenient method than serum sampling, which is associated with both collection difficulties and a high risk of occupational infection. In addition, our results show that PCR assaying of raw milk presented a more satisfying specificity than sensitivity in this research, which is in agreement with the conclusion given by previous studies (Hamdy and Amin, 2002; Al-Mariri and Haj-Mahmoud, 2010). Such results indicate that PCR assaying of raw milk is better suited to Brucella screening than diagnosis.

As a final consideration, vaccines have been used for control of bovine brucellosis as part of an established brucellosis control strategy in some areas and it has been reported that the Brucella vaccine strain can be present in the milk of vaccinated cows in their early inoculation period (Longo et al., 2009). The milk PCR method reported here was unable to distinguish between an animal infected with a virulent bacteria and one vaccinated with an attenuated strain. Therefore, screening results obtained using our method should be reviewed in conjunction with epidemiologic survey information.

In summary, to avoid possible brucellosis infections, detection of brucellosis via a regular campaign of PCR assaying of raw milk could be effective. Cows could be screened via regular raw milk checks and infected cows eradicated, thus helping to control the spread of Brucella. As a noninvasive sampling style, a raw milk PCR assay method could be used both as a food safety assessment method and as an attractive alternative for evaluation of Brucella infections in cows, particularly if used as a routine screening and surveillance tool to reduce brucellosis outbreaks.

\section{ACKNOWLEDGMENTS}

The authors thank Zengren Zheng, Jianmei Guo, and Hong Wang (all of China Animal Health and Epidemiology Center, Shandong, China) for their valuable technical discussion and encouraging support. This work was supported by public special research funds (200903055) from the Chinese Agriculture Ministry (Beijing, China).

\section{REFERENCES}

Al-Majali, A. M., A. A. Majok, N. M. Amarin, and O. F. Al-Rawashdeh. 2007. Prevalence of, and risk factors for, brucellosis in Awass sheep in Southern Jordan. Small Rumin. Res. 73:300-303.

Al-Mariri, A., and N. Haj-Mahmoud. 2010. Detection of Brucella abortus in bovine milk by polymerase chain reaction. Acta Vet. (Brno) $79: 277-280$.

Alton, G. G., L. M. Jones, and D. E. Pietz. 1975. Laboratory Techniques in Brucellosis. 2nd ed. World Health Organization (WHO) Monograph Series No. 55. WHO, Geneva, Switzerland.

Arellano-Reynoso, B., E. Diaz-Aparicio, M. Leal-Hernández, L. Hernández, and J.-P. Gorvel. 2004. Intracellular trafficking study of a RB51 B. abortus vaccinal strain isolated from cow milk. Vet. Microbiol. 98:307-312.

Bouza, E., C. Sánchez-Carrillo, S. Hernangómez, and M. J. González. and The Spanish Co-operative Group for the Study of Laboratory-acquired Brucellosis. 2005. Laboratory-acquired brucellosis: A Spanish national survey. J. Hosp. Infect. 61:80-83.

Bricker, B. J. 2002. PCR as a diagnostic tool for brucellosis. Vet. Microbiol. 90:435-446.

Chand, P., B. S. Rajpurohit, A. K. Malhotra, and J. S. Poonia. 2005. Comparison of milk-ELISA and serum-ELISA for the diagnosis of Brucella melitensis infection in sheep. Vet. Microbiol. 108:305311.

Corbel, M.J. 2006. Brucellosis in Humans and Animals. World Health Organization, Geneva, Switzerland.

Cordes, D. O., and M. E. Carter. 1979. Persistency of Brucella abortus infection in six herds of cattle under brucellosis eradication. N. Z. Vet. J. 27:255-259.

Earhart, K., S. Vafakolov, N. Yarmohamedova, A. Michael, J. Tjaden, and A. Soliman. 2009. Risk factors for brucellosis in Samarqand Oblast, Uzbekistan. Int. J. Infect. Dis. 13:749-753.

Falenski, A., A. Mayer-Scholl, M. Filter, C. Göllner, B. Appel, and K. Nöckler. 2011. Survival of Brucella spp. in mineral water, milk and yogurt. Int. J. Food Microbiol. 145:326-330.

Fiori, P. L., S. Mastrandrea, P. Rappelli, and P. Cappuccinelli. 2000. Brucella abortus infection acquired in microbiology laboratories. J. Clin. Microbiol. 38:2005-2006.

Gruner, E., E. Bernasconi, R. L. Galeazzi, D. Buhl, R. Heinzle, and D. Nadal. 1994. Brucellosis: An occupational hazard for medical laboratory personnel. Report of five cases. Infection 22:33-36.

Gupta, V. K., D. K. Verma, K. Singh, R. Kumari, S. V. Singh, and V. S. Vihan. 2006. Single-step PCR for detection of Brucella melitensis from tissue and blood of goats. Small Rumin. Res. 66:169-174.

Gwida, M., S. Al Dahouk, F. Melzer, U. Rösler, H. Neubauer, and H. Tomaso. 2010. Brucellosis - Regionally emerging zoonotic disease? Croat. Med. J. 51:289-295.

Hamdy, M. E. R., and A. S. Amin. 2002. Detection of Brucella species in the milk of infected cattle, sheep, goats and camels by PCR Vet. J. 163:299-305.

Longo, M., K. Mallardo, S. Montagnaro, L. D. Martino, S. Gallo, G. Fusco, G. Galiero, A. Guarino, U. Pagnini, and G. Iovane. 2009 
Shedding of Brucella abortus rough mutant strain RB51 in milk of water buffalo (Bubalus bubalis). Prev. Vet. Med. 90:113-118.

Malik, G. M. 1997. A clinical study of brucellosis in adults in the Asir region of southern Saudi Arabia. Am. J. Trop. Med. Hyg. $56: 375-377$.

Martin-Mazuelos, E., M. C. Nogales, C. Florez, J. M. Gómez-Mateos, F. Lozano, and A. Sanchez. 1994. Outbreak of Brucella melitensis among microbiology laboratory workers. J. Clin. Microbiol. $32: 2035-2036$

Nielsen, K. 2002. Diagnosis of brucellosis by serology. Vet. Microbiol. 90:447-459.

O'Leary, S., M. Sheahan, and T. Sweeney. 2006. Brucella abortus detection by PCR assay in blood, milk and lymph tissue of serologically positive cows. Res. Vet. Sci. 81:170-176.
Romero, C., and I. Lopez-Goñi. 1999. Improved method for purification of bacterial DNA from bovine milk for detection of Brucella spp. by PCR. Appl. Environ. Microbiol. 65:3735-3737.

Sewell, D. L. 1995. Laboratory-associated infections and biosafety. Clin. Microbiol. Rev. 8:389-405.

Vanzini, V. R., N. P. Aguirre, B. S. Valentini, S. Torioni de Echaide, C. I. Lugaresi, M. D. Marchesino, and K. Nielsen. 2001. Comparison of an indirect ELISA with the Brucella milk ring test for detection of antibodies to Brucella abortus in bulk milk samples. Vet. Microbiol. 82:55-60.

Xavier, M. N., T. A. Paixao, F. P. Poester, A. P. Lage, and R. L. Santos. 2009. Pathological, immunohistochemical and bacteriological study of tissues and milk of cows and fetuses experimentally infected with Brucella abortus. J. Comp. Pathol. 140:149-157. 